\title{
Spitballing, slapstick, lazzi and improvisation: The benefits of practising Commedia dell'Arte in secondary schools
}

\author{
Corinna Di Niro \\ University of South Australia \\ corinna.diniro@unisa.edu.au
}

\section{Pablo Muslera ${ }^{1}$}

University of South Australia pablo.muslera@unisa.edu.au

\begin{abstract}
Commedia dell'Arte is the 16th century genre of theatre from Italy where characters such as Pantalone, Dottore, Il Capitano and Arlecchino reappear in performances showcasing human frailties in comic ways. The term Commedia was initially used to describe "theatre" and Arte to describe one's trade or business. Now, commonly referred to as "the art of comedy", Commedia dell'Arte is often taught within the middle years of Australian secondary schools, where it is explored not just for the understanding of the genre itself, but more importantly to impart a number of theatre and life skills. Sometimes aided by an artist in residence or through viewing live Commedia dell'Arte performances, the slapstick manner and ensemble characteristics of Commedia dell'Arte players can serve as pedagogical tools to enrich the academic and personal lives of 21st century students. This article refers to a devised theatre play, The Marriage of Flavio and Isabella, which was developed as a contemporary Commedia dell'Arte performance and aims to show how the intrinsic characteristics of the genre can be translated to suit a contemporary Australian context. In doing so, the performance targets student-learning outcomes within Australian secondary schools. To devise the performance, I drew on my training and ten years of experience as a Commedia dell'Arte practitioner, the ideas and work of Antonio Fava, a leading expert in the genre, data collected from interviews with five professional Commedia dell'Arte practitioners, and interviews and participant observations with ten secondary school drama teachers. The purpose of drawing on a variety of sources was to explore the place and potential for Commedia dell'Arte in curriculum practice and to determine how Commedia dell'Arte could be better understood in a context where the genre is not part of the day-to-day culture. This article includes a discussion on Commedia dell'Arte's influence in
\end{abstract}


different genres and encourages a dialogue on how might the mode of performance embodied in traditional Commedia dell'Arte be translated to respond effectively to contemporary contexts, both educational and public.

Keywords: Commedia dell'Arte, Shakespeare, pedagogy, drama in secondary schools, Australia.

\section{Introduction}

One must learn by doing things, for though you think you know it, you have no certainty until you try.

(Sophocles 1906 [450 BC]: 191)

While the primary focus of this article relates to the benefits of teaching various Commedia dell'Arte elements, namely slapstick, lazzi and improvisation in secondary school drama classrooms in Australia today, the first step is to place the role of Commedia dell'Arte in theatre: throughout history until the present day. Considering Commedia dell'Arte is seen mostly as a form of comedy, an in-depth discussion of the role of comedy over time is offered. How Commedia dell'Arte influenced Elizabethan theatre is discussed to demonstrate Commedia dell'Arte's influence in other genres. This discussion is then followed by an examination of Commedia dell'Arte over time and place, and its role in the Australian drama curriculum, with reference to my own practice-led and qualitative research. From here, this article explores the creative artefact, The Marriage of Flavio and Isabella, as well as data collected from interviews with professional Commedia dell'Arte practitioners and interviews and participant observations with secondary school drama teachers to offer qualitative findings, which aim to contribute to the teaching of Commedia dell'Arte in secondary schools.

\section{Theatre and comedy: Why is comedy so much more challenging than tragedy?}

Theatre tends to divide itself into two forms: comedy and tragedy. The initial split occurred in ancient Greek theatre between 550 BC and 220 BC and today the iconic image of the sad and happy masks is the universal symbol used for theatre. Through centuries of reinterpretation, popular culture, education and social tastes, we now have many variations on the initial forms with performances that blend the two together; comedy appears in tragedies, and vice versa.

It seems that there is no concrete outline from which to define comedy as a form of theatre. As defined in Aristotle's Poetics 'the transformations which tragedy has undergone, and those responsible for them, have not been forgotten; but, because it was not taken seriously, little attention was paid to comedy at first" (Aristotle 1996: 9). Therefore, Comedy tends to be referred to as something that "delights", "amuses", "entertains" or "distracts" its audience for a brief moment in time.

For centuries, Comedy has been seen as the "lesser" in the hierarchy of theatre forms. Perhaps its low status arises from the long standing view that comedy is easy to perform as it is seen to be 'less 'weighty' than tragedy, less 'poetic' than the lyric, less 'meaningful' than the realist novel" (Bruce 2007: 75). Aristophanes, who considered comedies were more problematic 
to produce than tragedies, disagrees with this low status view. It is useful then to explore why Aristophanes sees Comedy as being more difficult than Tragedy (Aristophanes 1938 [424 BC]: ln. 515-520); it is not logical, it is not the same for everyone and as such there is no "formula". With no formula to draw on, it is difficult to perform with actors claiming, "you can't learn comedy, you either got it or you don't" (Aurther 2013). What is side-splitting humour for some is a mere giggle for others. Unlike Tragedy where hurt and suffering is universally understood, Comedy evokes a range of emotions unique to each person's experience. Additionally, Comedy can be seen as the absurdity of someone's tragedy and in order for the actor to reach the point of absurdity, they need to move past the immediacy of the dramatic action to embody the absurd. This is evident in the history of the clown where through comedy art imitating life is observed. As argued by McManus:

Fo wants us to recognise the essential clown-Auguste dichotomy in terms of class struggle, with Augustes representing anti-authoritarian, class-conscious values, and White Clown representing pawns of the existing power structure ... The clowns of Commedia dell'Arte were irreverent and anti-authoritarian some of the time, but they just as frequently underscored the status quo as undermined the power structure.

(McManus 2003: 16)

German philosopher Helmuth Plessner (1983) writes about the human condition or conditio humana. Plessner (1983) aims to determine the function actors played in understanding life, identity and the human condition. Fisher-Lichte (2002) connects Plessner's (1983) notion with the role of the clown and how this type of clowning is seen as an ideal method to reflect and mirror the human condition. Clown Auguste, more than white face clown, magnifies the frailty of the human condition through humour, as according to McManus (2003), the Auguste clown struggles to grasp cultural codes and social norms. Fisher-Lichte (2002) states that the human condition is seen through theatre as the "distance of the self from the self" by which one can confront, reflect and see their self, or the image of their self through another's eyes (FischerLichte 2002: 2), and this is recognisable in clown Auguste as art imitating life. As Fischer-Lichte (2002: 2) further states, "the actor is understood to be the very symbol and embodiment of the conditio humana".

In European theatre there has been a tradition for Comedies to subvert social order, taking the idea originally from Aristophanes. As observed in Clown, Greek theatre and Commedia dell'Arte, the idea to invert, reinvent and switch places in the name of poking fun at society are a continual and common thread among such forms of performance. The concept Aristophanes had of subverting social order was expanded upon through the professional players of the Commedia dell'Arte. Following on from the Renaissance, Commedia dell'Arte opened the doors for comedy to offer a lighter outlook on life by reinterpreting "the familiar" for the stage: troupes were successful in their abilities to "expose and subvert" social moves and hierarchy (Richards \& Richards 1990: 194). Through mocking scholars and Captains and the dynamics between lovers, Commedia dell' Arte promoted much of the comedy that "turned familiar authority structures and relationships upside down” (Richards \& Richards 1990: 194). Fischer-Lichte (2002: 5) reminds us that the European tradition of theatre "can be read as outlines or sketches of identity" and seldom has theatre "been satisfied with merely depicting social reality. It is far more to be understood as an integrated and integrating element of social reality" (Fischer-Lichte 2002: 5). It is this tradition that became popular in Commedia dell'Arte, which is perhaps why it is today commonly referred to as the "art of comedy". 


\section{The art of comedy}

Commedia dell'Arte emerged in the early 16th century from an economic and political crisis Italy faced at the time. While the actual translation of Commedia dell'Arte is closer to "theatre of the professionals" or "professional theatre", Commedia dell'Arte is typically seen in schools as the origin of comedy. Fava attributes this to the arrival of the organisation of the genre through fixed types:

By the late sixteenth century, Commedia, which is now termed "Perfect Comedy", counts on the presence of all the definitive types: male and female Servants, the Magnifico (Pantalone), the Dottore, male and female Lovers, and the Capitano.

(Fava 2004: 41)

As a genre of theatre, Commedia dell'Arte comprised many features that allowed for great amusement: physicality, the innovation of having females working alongside male actors, role reversal, and subversion of order to name a few. Fava reinforces this conceptualisation when he defines Commedia dell'Arte as "full, complete, total theatre, which includes all the techniques and disciplines of the varied forms of theatre. But Commedia remains an absolutely autonomous and independent genre" (Fava 2004: 14).

What aided the genre's success during this period was that the troupes effectively mastered the genre characteristics and a range of skills involving gesture, physicality, improvisation and body and voice exaggeration along with devising well thought-out scenarios that depicted immediate news relevant to the town they were performing in. The inclusion of topical information in each performance allowed for the performances to be placed in the context and lives of the audience, thus making the story lines significant to the time and place of each performance. Ultimately, this ability to plant itself in immediate life of the audience freed Commedia dell'Arte from "slavish adherence to classical modes" (Richards \& Richards 1990: 33). This capacity to blur both high and low culture for profit cemented Commedia dell'Arte's professional future.

According to Richards \& Richards (1990: 1), "the Commedia dell'Arte flourished for well over two hundred years, from the emergence of organised professional acting companies in the mid-sixteenth century through to the mid-eighteenth century". The genre gained much popularity beyond the Italian peninsula and quickly expanded throughout Europe, with troupes taking up residencies in Germany, Spain and France, to name a few. Commedia dell'Arte, thanks to its embodied techniques of recognisable character types and skills, at that time was considered new and interesting, much to the delight of the audiences.

Embodiment, or rather, human personality and behaviour, has been categorised by Commedia dell'Arte into four distinct character types (archetypes): Master, Captain, Lover and Servant. As a theatre form that depicts human frailties in comic ways, the archetypes evoke a connection with each audience member, as aspects of their lives are heightened and portrayed on the stage. Embodiment, as perceived on stage through Commedia dell'Arte, takes on MerleauPonty's (1962: 231) idea that "the body is not an object", but rather is "rooted in nature and the very moment when it is transformed by cultural influences, is never hermetically sealed and never left behind". Through Merleau-Ponty's work, it is possible to begin to understand how the actor embodies the attributes of the character. Commedia dell'Arte enables us to witness freely the impact of embodiment in that it is a genre of theatre where exaggeration is crucial to its realisation. This "art of comedy" leads us down the path of "art imitating life" through an array 
of skills where the lives of audience members are mirrored on stage and where scenarios filled with conflict and common human flaws are embodied and played out for the amusement of others. Such mastery continued beyond Commedia dell'Arte, expanding into melodrama, burlesque, slapstick comedy and of course in Elizabethan theatre where Shakespeare referenced a number of Commedia dell'Arte elements in some of his plays.

\section{Commedia dell'Arte's influence in Shakespeare}

On the surface, it is Shakespeare's comedies that one would expect to reference Commedia dell'Arte more than his histories, tragedies or "problem plays". Shakespeare's contemporary Ben Jonson used "Commedia dell'Arte-inspired physical comedy and posturing characters" (Dutton 2011: 489), for his popular Volpone (1605).

Although in 1592 another contemporary of Shakespeare's, Thomas Nashe, made the distinction between Commedia dell'Arte's inclusion of female actors and the English practice of all-male troupes, this is evidence that Commedia dell'Arte was in the Elizabethan playwrights' consciousness:

Our players are not as the players beyond the sea, a sort of squirting bawdy comedians, that have whores and common courtesans to play women's parts, and forbear no immodest speech or unchaste action that may procure laughter ... our representations ... [do not consist] like theirs of pantaloons, a whore, and a zany [figures in Commedia dell'Arte], but of emperors, kings and princes.

(Dillon 2006: 116)

Lea (1962: 432-433) draws some parallels between "Italian fiction" such as Commedia dell'Arte and Shakespeare's Merry Wives of Windsor: the "story of the husband who receives the lover's confidences and directs him how to proceed in his intrigue with his wife", and "many devices by which the lover might be conveyed away"; Coviello being carried inside a chest of lemons and (especially) Pantalone escaping under the laundry in a washtub -upon threat of the clothes being immediately boiled- recall Falstaff's own ordeals for the Wives' amusement.

Lea (1962: 434) adds that Shakespeare's probable first play, A Comedy of Errors, has "all the chief features of [Commedia dell'Arte] plays of mistaken doubles", and that the plots of both this play and The Tempest would not be out of place in Commedia dell'Arte's "stage traditions of the farces of mistaken identity, comic pastorals or shipwreck plays". Lea adds evidence for Commedia dell'Arte tradition in A Comedy of Errors:

By status the Dromios of Shakespeare's play are the slaves of Latin comedy, but in behaviour and misfortunes they are the servants of the Commedia dell'Arte. They are beaten as regularly as any Zanni and for the same reasons. The excuses that provoke misunderstandings are ordinary enough, the misdelivery of any small message or trinket will serve.

(Lee 1962: 438)

Helena, Hermia, Lysander and Demetrius of A Midsummer Night's Dream reflect "the vicious circle of enchanted lovers of the Commedia dell'Arte" (Lea 1962: 446). By contrast, Flaherty argues for the presence of Commedia dell'Arte characters in one of Shakespeare's most striking tragedies: Othello, the Moor of Venice. She interprets Greenblatt's reading of the Moor's tragedy - characters constantly improvising, and refashioning their "selves" - as having a strong parallel with Commedia dell'Arte dell'improviso (Flaherty 1991: 179). As evidence for 
Shakespeare's specific familiarity with Commedia dell'Arte, Flaherty offers a speech from As You Like It (II.vii.157-159): "the sixth age shifts/ Into the lean and slipper'd pantaloon/ With spectacles on nose, and pouch on side".

Commedia dell'Arte was and continues to be a highly influential form of theatre. This is evident in Shakespeare's work, right through to popular television sitcoms such as The Simpsons where Mr Burns, Mr Smithers, Homer, Bart and Lisa are inspired-by contemporary examples of Pantalone, Pedrolino, Pulcinella, Arlecchino and Colombina respectively (La Commedia dell'Arte 2015). It is evident that Commedia dell'Arte and life or the conditio humana run parallel.

\section{Commedia dell'Arte in the classroom}

We now arrive in the world of the drama classroom, a place that should not be devoid of humour. With a history that has traversed through time and culture, it is not by chance then that the classroom can call upon humour to enhance learning about life and that Commedia dell'Arte is one relied upon tool in this practice.

Australia's educational curriculum is changing and evolving. Until recently, there was a National Arts Education curriculum for reception to year ten, actioned at the state level. What one student would learn in arts education in the state of Queensland was not necessarily what a student would learn in the state of South Australia. Australia is now going through a process of curriculum change of the Arts for primary and secondary schools, moving from a state level to a new national level, with the aim of providing the same learning outcomes in Arts Education for all students across Australia.

The drama curriculum (both state and national) in secondary schools provides students with the possibility to learn a variety of life and theatre skills as opposed to the focus being on learning specified forms of theatre. While learning different styles of theatre and performing them is part of drama studies, the curriculum does not dictate what forms must be taught; rather it makes suggestions for which best express certain skills; Commedia dell'Arte is one listed option. The purpose to focus learning on theatrical and life skills through the arts is to equip students with a range of tools they can readily draw on in a variety of social, academic and corporate situations as demonstrated in the figure below. 


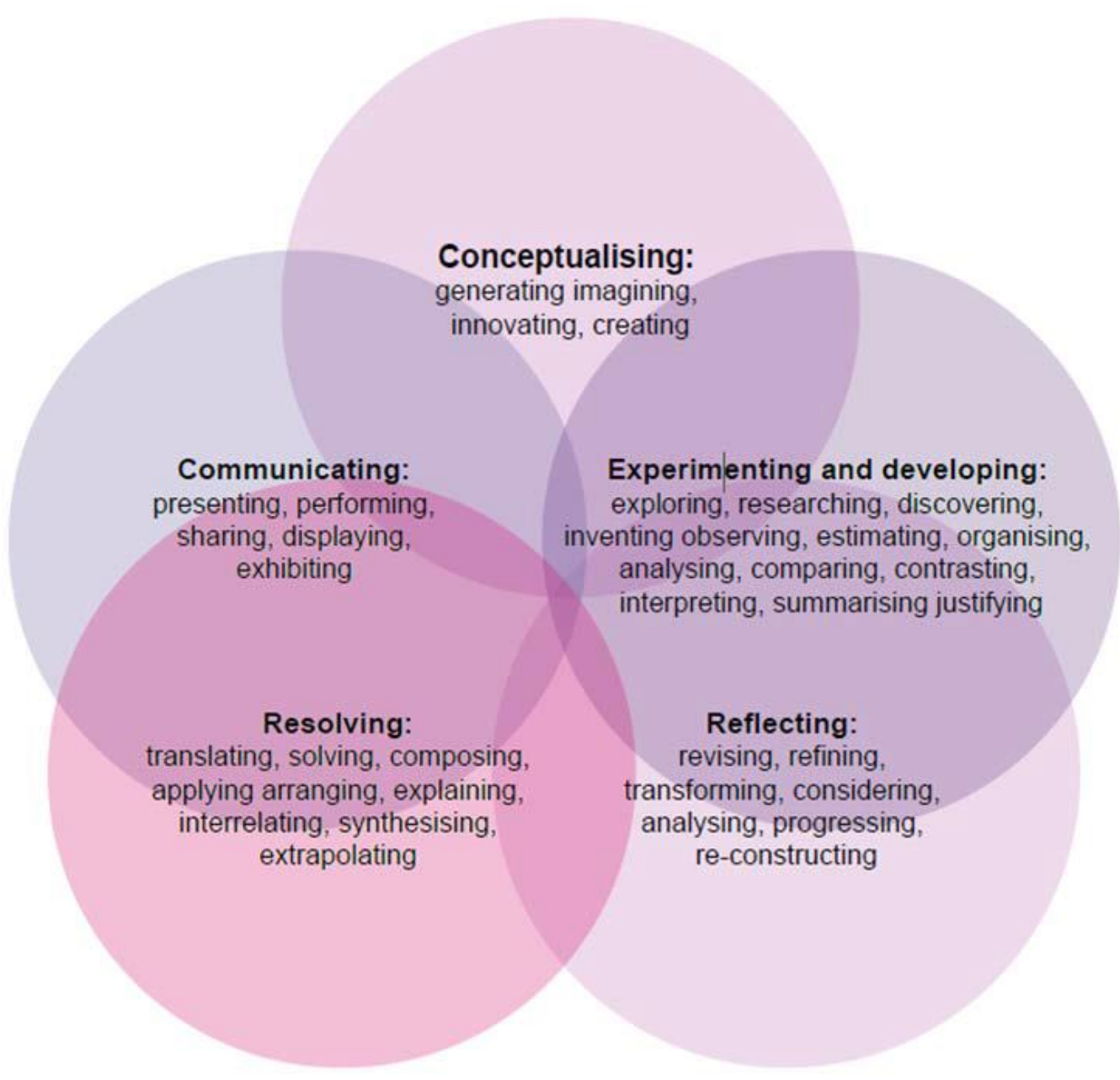

Figure 1. Learning in the Arts - Australian Curriculum: The Arts - Foundation to Year 10 (draft for consultation), Australian Curriculum Assessment and Reporting Authority 2012.

Within each of these macro-learning circles, teachers are able to pull from them a range of theatre and life skills, which can include group work, effective communication, quick thinking, physical and vocal expression, self-confidence, public speaking, improvisation, and understanding the relationships and dynamics in society through the study of archetypes. There is also a range of skills concerning the self that is important in drama studies as they aim to help students understand the role they play not only in their own immediate world but also in the greater world around them. This refers to the philosophical questions concerning the self: who am I, who can I be, what does it mean to be here in this classroom and in this play, and what do I need to let go of to be here? These sample questions are continuously reflected upon so that students may have the ability to extend themselves, make sense of the various relationships and conflicts not yet within their reach and to explore how they see themselves in the context of wider world.

In my role as a creative practitioner, I am aware that teachers see Commedia dell'Arte as a vehicle to teach such skills and therefore it is not by coincidence that Commedia dell'Arte can be aligned to a majority of learning outcomes required by the new National Arts Curriculum at the 
secondary school level in Australia. However, as part of the research, I wanted to find out what teachers who currently teach Commedia dell'Arte have to say about the role of the genre in schools. At the same time, I also wanted to discover how Commedia dell'Arte specialists work with the genre in diverse contexts, as these practitioners are available to run workshops for teachers and students and to provide opportunities for school groups to view their productions. Below is outlined the research methodology and subsequent findings.

\section{Methodology}

Researching the benefits of practising Commedia dell'Arte in secondary schools involved engaging with two distinct groups: Commedia dell'Arte practitioners and drama teachers. Using qualitative data collection methods, I first interviewed five self-acknowledged Commedia dell'Arte specialists living in Australia, Italy, the United States and the United Kingdom to identify when placed in diverse contexts, how far the Commedia dell'Arte characteristics are malleable before a performance is no longer recognisable with the genre. The purpose in doing so was to consider how the genre is understood in varied contexts.

I then interviewed and observed ten drama teachers currently teaching Commedia dell'Arte in secondary schools in South Australia. The purpose was to identify what information about Commedia dell'Arte is being taught, the benefits these teachers feel teaching this genre has for their students, and to determine what these teachers themselves know about Commedia dell'Arte. Observations involved visiting classrooms for the full term to view what methods teachers used to teach Commedia dell'Arte to their students, how students engaged with the material and how a unit of study around the genre was shaped.

The students ranged from years eight to ten in each of the classrooms visited. Each classroom was preparing for a polished public performance that on the whole was announced to the students in the first week of their Commedia dell'Arte lessons. The teachers stated that by week ten their students would be expected to perform their own devised Commedia dell'Arte play and that their teacher would teach some Commedia dell'Arte skills and help polish their productions along the way. The public performances ranged from an audience of children aged six-ten to an evening event for parents and friends, held either at the school or in a theatre venue. The students were being assessed on their performance as well as their understanding of the genre and their participation in class.

With the information garnered from both sources, as well as my own research, training and knowledge of the genre, I used a practice-led research method to develop a new Commedia dell'Arte performance that drew on the genre characteristics, but updated them to suit a contemporary Australian context. The rationale for finding ways to update the genre characteristics was to test whether the performance could be seen as being relevant to a contemporary audience and thus a relevant tool for strategies to engage students in the genre.

\subsection{Findings: Commedia dell'Arte specialists $-\mathrm{A}$ traditional genre responding to a contemporary context}

Five specialists were interviewed who each acknowledged Commedia dell'Arte as a genre of theatre to itself, existing within a fixed framework. While the specialists agreed with Fava's (2004: 127) notion that four of the five reference points: mask, improvisation, multilingualism, and archetypes are "indispensable", each specialist acknowledged that they need to play with the 
weight and level of importance each reference point has within their own contemporary context (see Appendix for description of reference points). Predominately, these specialists serve as resources to introduce Commedia dell'Arte to teachers, students and general audiences, as a genre relevant to today but to a degree unfamiliar to most.

Based on these interviews, the key strategies for teaching and performing Commedia dell'Arte range from staying very close to the reference points to keeping just one or two of them. Hawes, who is based in the United Kingdom, understands that the British audience has "traditionally stayed well away from Commedia dell'Arte" (Hawes 2012, pers. comm. 24 June) and felt disconnected to his performances when the Commedia dell'Arte mask was always present. To connect with his audience, he included moments of taking off his mask and talking directly to the audience as himself (the actor), which kept the audience following along with the plot. Hawes (personal communication, 24 June 2012) stated the result was positive: "the audiences responded immediately and suddenly we were free". Contrastingly, Margio (2012) who is based in Perth, Western Australia believes that all the reference points of Commedia dell'Arte can be stripped back, except for the mask. Holding the opinion that "Perth lacks a connection to the rest of Australia and sometimes the world" (Margio, personal communication, 27 July 2012), he has needed to reassess the importance of the reference points in order to encourage an awakening of Commedia dell'Arte in Perth.

Commedia where actors are dressed like today and deal with issues of today I don't have a problem with but when you take the mask off that for me is the question mark ... would I still then call it commedia ... I don't think so.

(Margio, personal communication, 27 July 2012)

What this data reveals is that like audiences, each learning context is unique and as such, the teacher needs to be as malleable as the genre does in order to get the best results from their students. Does performing with the mask discourage or benefit the students? Can the genre be made more relevant if the students wore contemporary outfits as opposed to historical costumes? How far can the reference points of Commedia dell'Arte be modernised before what is being performed or taught is no longer recognisable within the Commedia dell' Arte system?

\subsection{Findings: Drama teachers - The pressure to perform}

The interviews indicate that Commedia dell'Arte is taught from years eight to ten and is seen as one of the few comical genres that could link itself to the majority of skills required to teach at the secondary school level as further outlined below. It was also considered to be the most called upon comic form of theatre due to its universal values and ability to plant itself in the immediacy of life. As one teacher noted:

Even though it is not actually on the curriculum it is widely taught. It opens students up to an understanding of life through techniques you don't find in other forms of theatre. It really helps you build character archetypes relevant to today.

(Teacher B)

What also yielded from the data was that despite teachers having minimal training in the genre themselves, and in some cases no training, they saw value in teaching Commedia dell'Arte, as it catered best to curriculum and student needs. 
I teach Commedia dell'Arte because nowhere in the curriculum does it pinpoint what content you need to cover. It only lists what skills you need to teach during secondary school drama and I find through various elements like lazzi, improvising and slapstick, all of them exist in Commedia dell'Arte.

(Teacher G)

This reveals that despite limited knowledge in the genre, teachers recognise Commedia dell'Arte's ability to link in with the range of student learning outcomes as outlined in the drama curriculum. Further, teachers see the value of teaching the genre as they themselves consider Commedia dell'Arte to offer a range of philosophical, life and theatre skills and therefore continue to teach it.

When observing the drama teachers, and upon hearing the expectation that their students would need to devise their own Commedia dell'Arte play and perform it within 10 weeks, I immediately suspected that this task would be too difficult to complete with any level of polish in mind due to the limited time imposed. The timeframe allocated for a unit of Commedia dell'Arte work in each school averaged at eight weeks of rehearsal, with one or two weeks dedicated to costume and props with the final drama lesson reserved for the performance, if not held in the evening of the final week. Typically each drama class met three times per week for one double lesson (90 minutes) and two single lessons (45 minutes each), giving the students three hours of Commedia dell'Arte each week. With a class size of approximately 15 to 21 students, the teachers divided their classes into two or three groups with somewhere between seven and eleven students per group. This meant the teacher needed to give equal attention to each group, which in turn required the students to have manageable tasks that they could work on separately in their own groups. In more cases than less, students could not use this time to their advantage, as they were unable to focus on devising their play because they had no basic understanding of the Commedia dell'Arte structure from which to create scenes from.

To compare, it took three professional actors three months of four three-hour rehearsals each week to create the pilot version of The Marriage of Flavio and Isabella and another six-week block of two three-hour rehearsals each week to create the final version. While the expected outcomes were indeed different between the student groups and the actors' performance, demanding a rushed performance outcome to a group new to the genre on the whole did not produce positive results. In all but one case, the final show was in some way edited or re-named as a "work in progress" as the teacher felt the students did not grasp the genre well enough to put on a polished performance as initially requested of them in week one.

While it appeared through the interviews that the teachers understood the role Commedia dell'Arte has in secondary schools, and were familiar with the curriculum focusing on skill development as opposed to learning and performing full theatre forms, this was not being transmitted to the students. From the observations, rarely did I observe teachers teaching skills without connecting them to a performance outcome. No time could be given to students playing with different elements such as slapstick, lazzi and improvisation as the unit of study was aimed towards producing a performance piece and not towards developing theatre and life skills or at answering philosophical questions concerning the self.

In one particular observation study, there was a sense of panic by the teacher who had particularly identified during the interview as having no understanding of Commedia dell'Arte or any training in the genre and that this was their first time teaching it. On week five of the observation, the teacher told me, "they're not getting it, they're just not getting it" (Teacher A), referring to their students unable to devise their own Commedia dell'Arte play. It was clear that 
Teacher A was nervous about the final performance not being polished and this seemed to be more important to the teacher than the skills being taught. The result was moments before the performance, Teacher A told their students, "we'll just call it a work in progress" (Teacher A).

\section{Discussion and reflection}

While observing Teacher A, I noted from the very beginning that even though the students did not understand enough about Commedia dell'Arte in order to produce any devised work, this was not the root of the problem. The students had no concept of what it meant to work as an ensemble, making it clear that they did not feel safe to let go of their inhibitions in order to take on different personas or "act silly" in front of their peers.

Furthermore, Teacher A did not invest time in any team building exercises or improvisational games to help develop quick thinking skills or to introduce the idea of "physical problematising"; a creative brainstorming approach I have developed, which is carried out during active rehearsals, where in essence, students collaboratively write the script with their bodies. Through observing the lessons, the students did not appear free to explore the physical nature of Commedia dell'Arte as they were self-conscious and treaded with caution to avoid making fools of themselves and being laughed at by their peers. The problem here was that it was term one, the class were unfamiliar with each other and were not given any time to develop a sense of trust with each other before being thrown into learning a physically demanding genre that exaggerates life on the stage for the audience's amusement. It was clear that attempting to teach Commedia dell'Arte with a performance outcome to a group unfamiliar to this style of drama was a poor choice that ultimately had steered away from the aims and objectives of the curriculum.

All participant observations were conducted in term one of 2012. When asked why Commedia dell'Arte was taught early on in the school year, there were two common answers: (1) it seemed a good choice to hook students into studying drama because it is a comical form and students seem to prefer comedy over tragedy, and (2) it is easy to teach. As one teacher noted, "I use it [i.e., Commedia dell'Arte] to introduce theatre to my students. This is the first type of theatre they learn because it's the easiest" (Teacher C). The misconception that Commedia dell'Arte is easy to teach when aiming for a performance outcome was what generally led the teachers observed into trouble when allocating time for their students to study the genre.

Based on the interviews and observations, it was evident that there was a need to demonstrate to the teachers how best to break down Commedia dell'Arte into a more manageable unit of study that connects to the curriculum and provides an opportunity for the students to showcase their newly learnt skills. To do so, next I offer three elements of Commedia dell'Arte that could be effectively taught to years eight to ten, which not only meet curriculum needs but provide scope for placing a Commedia dell'Arte performance or scene in a contemporary setting with modernised character traits so that the genre remains relevant to a contemporary context.

\section{The benefits of learning Commedia dell'Arte fundamentals}

When performed and taught as part of the fixed framework that supports Commedia dell'Arte, known as the five reference points, slapstick, lazzi and improvisation sufficiently support the overall aims and objectives of the curriculum. These elements will now be explained with 
examples of their use as demonstrated in the creative artefact, The Marriage of Flavio and Isabella.

\subsection{Slapstick}

Referring to the actual comic weapon used by the servants in Commedia dell'Arte, the slapstick (batòcio) is a wooden parody of a sword made up of two "blades" tied together at one end by string; when it strikes someone or something, it produces a loud noise. The sound gives the impression that the strike is painful but in reality it does not cause any physical pain (Fava 2004).

The slapstick is, however, more than a comical weapon; it is also considered the "inseparable pal" of the servant (Fava 2004: 170). The slapstick is viewed as the servant's universal tool and it is here where slapstick play directly benefits students. As seen in The Marriage of Flavio and Isabella, the slapstick serves as an array of tools restricted only by the actor's imagination. As the creative artefact has been developed as a resource for secondary schools, the examples of particular elements are aimed at the teenage level; not reduced or "dumbed" down to a simplified level, but rather pitched just within their reach so that they can use the examples as a spring board to further develop their own ideas. The following is an example of how the slapstick might become a back-scratcher.

The rude and vulgar lifestyle of the servants in Commedia dell'Arte is a fun exploration with the assistance of the slapstick. Life as a servant living outdoors means that showers, clean clothes and food are luxuries. Rather, the flea-infested servants who scrounge around rubbish bins eating food scraps revel in a bowl of flies or a good-old scratch to satisfy their needs.

Arlecchino, Scapino and Bagattino, the three lower-class servants from The Marriage of Flavio and Isabella open the performance with a sleep machine (this will be further explained in Lazzi). They are sleeping in the piazza in a very physical and vocal manner. As part of this sleep machine, Arlecchino, Scapino and Bagattino exchange in a pattern of scratching, yawning and farting, while sleeping. As the momentum of the sleep machine progresses, so do the various actions. Using the slapstick, Arlecchino is scratching all over his body; he has fleas. The slapstick becomes a back-scratcher, immediately recognisable by the actor's actions. The scratching crescendos from his back to his chest, legs, head and arms, indicating the fleas have taken over his body.

\subsection{Lazzi}

The plural term in Italian meaning types of developed gags. "A minimal lazzo is a quick gag, a maximum lazzo is a brief, fully-structured scene" (Fava 2004: 37). In The Marriage of Flavio and Isabella, lazzi exist in every scene. The following is one explanation of one maximum lazzo.

In its simplest definition, the "sleep machine" is a machine that produces sleep, repeating itself over a prescribed period of time, stopped by some type of external force, for example the rain, or in the case of The Marriage of Flavio and Isabella, the noise of the audience wakes the three servants, thus stopping the action. The performance machine is designed like any other machine, but here the characters are the individual cogs. The idea of the sleep machine lazzo is twofold: to showcase the physical and vocal nature of Commedia dell'Arte and to express the vulgar manner in which those servants who live outside behave. The aesthetics of this lazzo vary according to the age group of those creating it or for who is the target audience. In The Marriage of Flavio and Isabella, Arlecchino (standing) farts and this causes Scapino (sitting on the ground behind Arlecchino) to faint. Bagattino, who is sitting on a chair behind Scapino, is yawning and 
scratching and continues to accidently collide his slapstick with Scapino's each time Scapino faints. This in turn causes Scapino to wake up and sit up again, only to be farted on again by Arlecchino, and the cycle repeats itself. On top of the physical demonstration is the vocal one whereby a series of slaps, snores, yawns and fart sounds contribute to the overall success of the lazzo. Within this, each character can further develop their only behavioural nuances, such as Arlecchino's flea dilemma explained previously.

\subsection{Improvisation}

Improvisation is both a reference point and a skill in Commedia dell'Arte. The study of improvisation as a rehearsal method differs greatly to that of pure improvisation, which is a technique that occurs in front of the audience. In Commedia dell'Arte, both types of improvisation are used; however, it is the method of devising a non-scripted performance which underpins Commedia dell'Arte's connection to the school curriculum. Therefore, The Marriage of Flavio and Isabella uses improvisation as a method to develop the script and live improvisation when interacting with audience members, and encourages students to apply this technique when devising their own short scenes. Improvising the characteristics of the archetypes and how they move during rehearsals enables students to develop their own dialogue right there, in the moment, on their feet. This differs greatly to learning lines and attempting to put actions with prearranged dialogue. Interestingly, teachers acknowledged in their interviews that this physical aspect and developing the skill of devising dialogue was what they struggled with most frequently.

I'm not comfortable with demonstrating the postures, interactions and walks of the archetypes and I don't know what to say. I guess it is because I don't know how to do it. How do you just come up with lines on the spot that make sense to that character? I know that my lack of knowledge in this area tends to mean that this is the part of Commedia dell'Arte that my students get stuck with too.

(Teacher E)

The Marriage of Flavio and Isabella was devised through a process of improvisation, which is the same process used in secondary schools for non-scripted theatre forms. The "script" is only a scene-by-scene outline of the action of the play, rather than a traditional script with dialogue. The dialogue is recalled during the performance and in part improvised depending on audience reactions. To create The Marriage of Flavio and Isabella, the cast members physically and verbally improvised a number of scene suggestions that emerged during the rehearsal process through physical problematising. This notion to jump in and start creating is further supported by Haseman (2006) in terms of a practice-led research, who states, "researchers tend to 'dive in' to commence practising to see what emerges" (Haseman 2006: 4). Once the skeleton of the storyline was developed, the cast experimented with dialogue until they reached a point where they felt they had enough material. The final stages of the rehearsal process were dedicated to refining: perfecting and fixing the dialogue so that it became a loose script that was then memorised by the actors. 


\section{The application of Lazzi, improvisation and slapstick to the learning environment}

When put together, slapstick, lazzi and improvisation serve as practical skills to enhance student learning. If we take one aspect of practice here, the sleep machine, and ask students to develop this in small groups, the following skills in relation to Figure 1 above are explored and taught: working with slapsticks allows students to conceptualise through generating ideas and using their imagination. What else can the slapstick do aside from hitting something or someone? As they explore the realms of this, they are pushing themselves to think beyond the literal sense and inviting a range of possibilities that at face value would be unfamiliar to them. The aesthetics of the slapstick may at first limit a student's possibility to look beyond the design of the prop to see the slapstick for something more than its basic function. However, through physical problematising and through observing fellow students, they can pick up on new ideas and replicate them in their own exploration, all the while comparing and contrasting this to either a resource such as The Marriage of Flavio and Isabella or to feedback from teachers and peers. Additionally, working with a prop and its weight asks students to consider the safety of themselves, their fellow actors and the audience, which are also other important theatre and life skills.

Developing a lazzo involves working as an ensemble and as such allows students to interpret, organise and research how their ideas will match and fit the larger aims of the group and how to communicate their ideas within a team environment. There is a focus on resolving issues to compose a lazzo and learning how to effectively share the space for good stage composition. This physical problematising invites students to gain skills in self-confidence to offer ideas, sharing, listening, group work, making eye contact, and to have safe body and spatial awareness.

Improvising as a method of rehearsing asks participants to continually reflect upon their work through revising and refining, and re-constructing when the scene does not work. Problem solving, communication and justifying actions are also important aspects here. Through the rehearsal process, the teacher may ask to see the work and so elements of presenting, performing and sharing are also called upon. Viewing other students' work invites students to develop constructive criticism and reviewing skills. Additional skills can also include effective communication, quick thinking, physical and vocal expression, public speaking, and understanding the role of archetypes in society, which are effectively explored when done through physical problematising.

As evident here, just three elements of Commedia dell'Arte can cover a large proportion of the learning outcomes for students, highlighting that there is no need to teach Commedia dell'Arte in its entirety in years eight-ten. Also, because of the broad range of skills underpinning each element, Commedia dell'Arte is not an easy genre to teach when placed in the context of building towards a performance in only ten weeks: the precise physicality of each character alone could take up an entire unit of study.

When the pressure to not perform is removed, Commedia dell'Arte can open a new discourse for self-discovery in the drama classroom. Through a practical analysis of the archetypes whereby students get up and create certain scenarios embedded with the three elements discussed, it allows for students to enjoy being in the state of play and to be free from their traditional school, home, or sport labels. If taught well, an entire scene can emerge from something as simple as a hungry servant attempting to catch a fly, or a greedy politician on a 
mission to cut funding, and the list of skills learnt to realise these scenes along with the philosophical questions it raises would be ample to fulfil the curriculum needs of drama in the early to middle years of secondary school.

\section{Conclusion}

If the main outcome for students in years eight to ten is not to learn an entire form of theatre but to develop a range of important skills, why then is there a need to produce fully fleshed out theatre performances of Commedia dell'Arte? While I agree that there is a need to introduce the idea of being involved in a play both on stage and off before studying drama in years eleven and twelve, where the curriculum calls for mid-year and end of year productions of a polished scale, the productions of students in the younger years could be better aimed towards a showcase of skills to remove the unnecessary pressure of learning a complete genre. The reflection that follows could then focus deeper on how students felt physically problematising elements of Commedia dell'Arte and how this contributed to learning a number of the skills previously discussed.

As argued throughout this article, Commedia dell'Arte has the ability to educate students in a range of theatre roles and skills, it can teach students about their own life and how their world fits into a broader one, allowing them to learn about cultural and social similarities and differences through a practical exploration of the archetypes. There are many elements that contribute to Commedia dell'Arte; this article has signified three. The realisation of full and complete performances is not essential to the learning requirements as required by the National Arts Curriculum and, as this research has shown, is unrealistic. Rather, it is the study of these elements that results in students and teachers meeting the learning outcomes prescribed. Therefore, on the basis of the interviews, observations and my own creative practice, if Commedia dell'Arte is to remain as a genre taught at the beginning of the academic school year as a method to attract students to drama, then it should be taught as an introduction to skill development.

As a Commedia dell'Arte practitioner working closely with drama teachers myself, I have understood that it is impossible to re-enact the genre as it once was. Rather, it is the core characteristics of the genre that need to be adjusted so that the performance connects with a contemporary audience. When the essence of the genre, that is, an understanding of what the theatre was like when it was first performed and information about the culture that first saw the performance, is understood, then this knowledge allows teachers to develop a unit of study that will inspire and energise today's students.

\section{Notes}

${ }^{1}$ Corinna Di Niro is the main author of the paper and Pablo Muslera is the author of section four.

\section{Appendix}

Fava's Five Reference Points 
Mask

The mask implies both the physical mask and the invisible mask (persona) adopted for all nonmasked characters. Linking this to Merleau-Ponty's (1962) theory of embodiment, the mask, whether physical or metaphoric, allows for the actor to step outside of himself and to adopt a new identity.

\section{Archetypes}

Formed with the idea they represent all of humanity, the Commedia dell'Arte cemented what previous artisans were starting to develop: Master, Servant, Lover, and Captain. These archetypes refer to the stages of life whereby numerous characters exist within each. They are used as the basis from where one can exaggerate the life of another or themselves.

\section{Improvisation}

Both a core principle required in Commedia dell'Arte and a theatre skill taught at the secondary school level in drama. Improvisation is the process used during rehearsals where scene ideas are discussed and the dialogue improvised until reaching a level ready for performance. While improvisation did occur live in front of the audience in Commedia dell'Arte plays, the pre-devised scenario created and learnt during rehearsals controlled it.

\section{Multilingualism}

During the early 16th century when Italy lacked an official language, different regions spoke their own dialects. When troupes visited to perform in these different regions, audience members could understand at least one language with the rest of the play understood by body and gesture. The idea of performing in a multilingual fashion gave emphasis to the gesture, showcasing the actors' physical skills.

\section{Anachronism}

Refers to a shoe for a phone, an oversized object that does not belong, or an element connected with a specific time period that if placed outside its proper chronological territory is incorrect. This reference point is considered an elective point and not as essential as the other four.

\section{References}

Aristophanes. (1938 [424 BC]). 'Knights', in O’Neill, E. (ed.), The Complete Greek Drama. Vol. 2. New York: Random House, pp. 515-520. Available online: http://www.perseus.tufts.edu/hopper/text?doc=Perseus\%3Atext\%3A1999.01.0034\%3Acard\% 3D507 [Accessed on 4 September 2015].

Aristotle (1996). Poetics (trans. M. Heath). London: Penguin.

Aurther, Owain. (2013). Verbatim from 'Artist Talk'. One Man, Two Guvnors, National Theatre of Great Britain Australian Premiere, National Adelaide Festival, 5 May.

Australian Curriculum Assessment and Reporting Authority. (2012). 'Learning in the Arts Australian Curriculum: The Arts - Foundation to Year 10 (Draft for consultation)'. Available online:

http://www.acara.edu.au/verve/_resources/DRAFT_Australian_Curriculum_The_Arts_Found ation_to_Year_10_July_2012.pdf\#search=arts [Accessed on 11 March 2013]. 
Bruce, S. (2007). 'Shakespeare: The comedies', in Hiscock, A. \& Hopkins, L. (eds.), Teaching Shakespeare and Early Modern Dramatists, Basingstoke: Palgrave Macmillan, pp. 75-90.

Dillon, J. (ed.) (2006). The Cambridge Introduction to Early English Theatre. Cambridge: Cambridge University Press.

Dutton, R. (ed.) (2011). The Oxford Handbook of Early Modern Literature. Oxford: University Press.

Fava, A. (2004). The Comic Mask in the Commedia dell'Arte: Actor Training, Improvisation, and the Poetics of Survival. Reggio Emilia: Arscomica.

Fischer-Lichte, E. (2002). History of European Theatre and Drama. Transl. by Riley, J. New York: Routledge.

Flaherty, T.J. (1991). "Othello dell'Arte": The presence of "Commedia" in Shakespeare's tragedy'. Theatre Journal 43 (2), pp. 179-194.

Haseman, B. (2006). 'A manifesto for performative research'. Media International Australia Incorporating Culture and Policy. Quarterly Journal of Media Research and Resources 118, pp. 98-106.

La Commedia dell'Arte. (2015). 'The characters'. Available online: https://sites.google.com/site/italiancommedia/the-characters [Accessed on 4 September 2015].

Lea, K.M. (1962). Italian Popular Comedy: A Study in the Commedia dell'Arte, 1560-1620 with Special Reference to the English Stage. New York: Russell \& Russell.

McManus, D. (2003). No Kidding!: Clown as Protagonist in Twentieth-Century Theatre. Delaware: University of Delaware.

Merleau-Ponty, M. (1962). Phenomenology of Perception. London: Routledge.

Plessner, H. (1983). Conditio Humana. Berlin: Suhrkamp.

Richards, K. \& Richards, L. (1990). The Commedia dell'Arte: A Documentary History. Oxford: Basil Blackwell for the Shakespeare Head Press.

Sophocles. (1906 [450 BC]). 'Trachiniae', in Young, G. (transl.), The Dramas of Sophocles, London: J. M. Dent \& Co., pp. 174-191. 